\title{
Interest of indirect photometric detection in liquid chromatography of inorganic anions in natural waters
}

\author{
S. Lazar ${ }^{1}$, B. Herbreteau ${ }^{2 *}$, M. El Haddad ${ }^{1}$, M. Lafosse ${ }^{2}$, M. Akssira ${ }^{1}$ and M. Dreux ${ }^{2}$ \\ ${ }^{1}$ Laboratoire de Chimie Bioorganique et Analytique, FSTM, Université Hassan II, BP 146, Mohammédia, Marocco \\ ${ }^{2}$ Institut de Chimie Organique et Analytique, UPRES-A 6005, Université d'Orléans,
} BP 6759, 45067 Orléans cedex 2, France

\begin{abstract}
Using a convenient mobile phase (1 mM o-phthalic acid-TRIS buffer/acetonitrile), an ion chromatographic system is proposed for analysis of main inorganic anions (chloride, nitrite, bromide, nitrate, phosphate, sulfate) in natural waters by using indirect photometric detection. The main reason for the detector choice was that UV detectors are widespread in educational and low level equipment laboratories. Indirect photometric detection is an attractive and inexpensive approach and the system is versatile.
\end{abstract}

Keywords. Ion chromatography - natural water - conductivity detection - indirect photometric detection.

\section{Introduction}

Environmental analysis, such as the determination of inorganic anions in water, has become inescapable in analytical chemistry. Inorganic anion chromatography [1-3] on anion exchange column is a standard analytical methodology and only some references are given. Detection is mainly performed by indirect photometry [3-5] introduced by Small and Miller [6] or conductivity with or without chemical suppression [7-11]. The aim of this work was to confirm the convenience of a simple and conventional liquid chromatographic system (isocratic pump, manual injector, column, UV detector and integrator), which is available in all analytical laboratories, for main anion analysis in water samples.

\section{Experimental}

The liquid chromatograph consisted of an isocratic pump (Spectra Physics, Isochrom LC), an injector (Rheodyne 7125) equipped with a $150 \mu \mathrm{l}$ sample loop, a $150 \times 3 \mathrm{~mm}$ anion exchange column (Anion Dual 1, Metrohm) equipped with a guard column, a conductivity (Vydac 213A) or a UVspectrophotometric (Kratos SF769) detector and an integrator (Shimadzu CR5A). The injection volume was $150 \mu \mathrm{L}$. For conductivity detection, the column, injector and conductivity cell were thermostated at $30{ }^{\circ} \mathrm{C}$ with an LC oven. Temperature control was not required for indirect photometric detection.
All chemical reagents were of analytical grade. The eluent was a 98/2 ortho-phthalic acid-TRIS buffer/acetonitrile mixture at a flow-rate of $0.8 \mathrm{~mL} \cdot \mathrm{min}^{-1}$. TRIS was used to adjust the $\mathrm{pH}$ value. In all mobile phases (even if not specified in the text), $2 \%$ (v/v) acetonitrile was added in order to avoid microorganism proliferation.

For quantitation, all injections were made in triplicate. External standard calibrations were made using $510^{-5}, 10^{-4}$, $510^{-4}$ and $10^{-3}$ mol. $\mathrm{L}^{-1}$ solutions of each inorganic anion in deionized distilled water. The correlation coefficients of calibration curves in log-log coordinates were better than 0.999 and 0.991 , for indirect photometric and conductivity detection, respectively and RSD was approximately $2 \%$.

\section{Results and discussion}

Aromatic acids, such as phthalic acid, are generally used as the visualization agent. It is well known that the competing ion concentration and the eluent $\mathrm{pH}$ affect the retention of inorganic anions $[1,3]$. The first eluent we used was an $8 \mathrm{mmol} . \mathrm{L}^{-1}$ phthalic acid-TRIS $\mathrm{pH} 4$, which is recommended by the column supplier. However, as far as detection is concerned $[1,3]$, decreasing the phthalic acid concentration induces a decrease in the eluent conductivity (favorable to conductivity detection) and allows the use of a lower wavelength without saturation of the UV detector (favorable to indirect photometric detection). The use of low concentration allowed setting the UV detector at $273 \mathrm{~nm}$ where spectrum slope is around 0 (shoulder) and the initial absorbance is 0.7-0.8 AU. This provided higher sensitivity and stability

* Correspondence and reprints.

Received March 31, 1999; revised October 27, 1999; accepted December 17, 1999. 


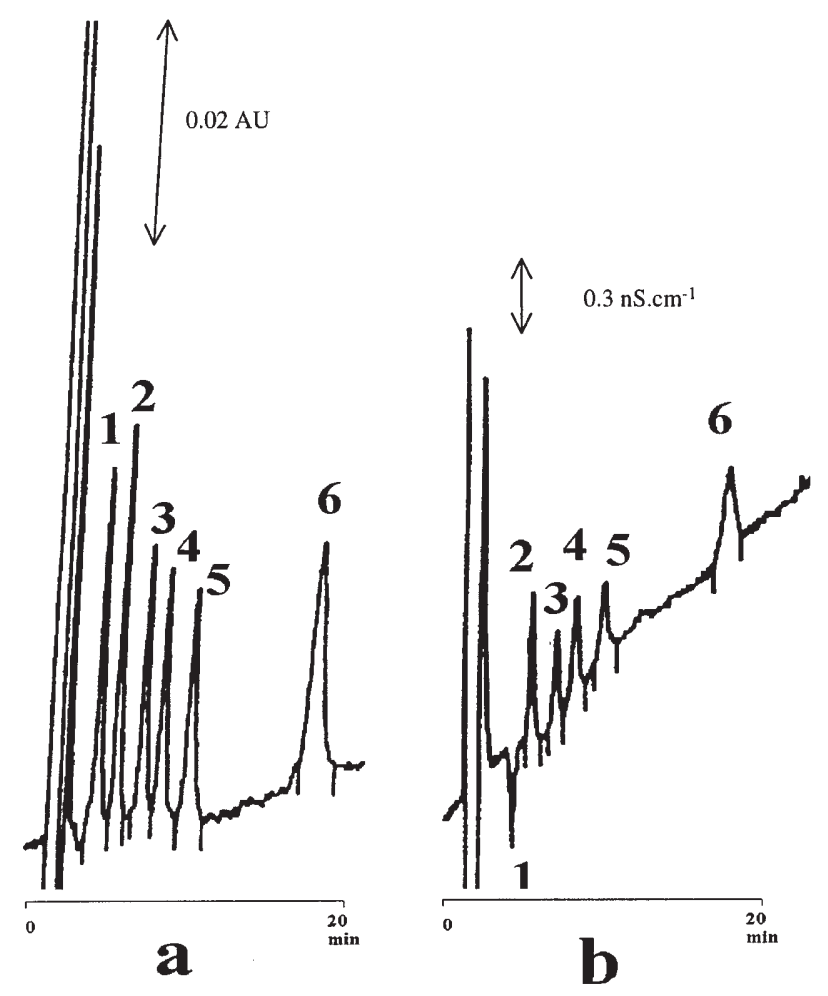

Fig. 1. Chromatograms of a $510^{-5}$ mol.L $\mathrm{L}^{-1}$ standard solution using (a) indirect photometric at $273 \mathrm{~nm}$, (b) conductivity detection. Eluent: 98/2 1 mmol.L $\mathrm{L}^{-1}$ phthalic acid - TRIS pH 5.7 /acetonitrile. Peak identification: (1) phosphate, (2) chloride, (3) nitrite, (4) bromide, (5) nitrate, (6) sulfate. as it was noticed for pyromellitate buffers as eluent [3]. Buffer capacity remains sufficient at $1 \mathrm{mmol} . \mathrm{L}^{-1}$ phthalic acid-TRIS, pH 5.7 (Fig. 1a and b) but lower concentrations induced instability of the baseline. A peak system was observed using the $8 \mathrm{mmol} . \mathrm{L}^{-1}$ eluent (at elution volume $12 \mathrm{~mL}$ ) but was not observed using $1 \mathrm{mmol} . \mathrm{L}^{-1}$ eluent.

Such recent stationary phase allows efficient univalent and divalent anions separations with an acceptable retention time using low phthalic acid concentration bearing apparent charge from -1 to -2 . As expected $[1,3]$, retention decreased as a function of $\mathrm{pH}$ value because of the change in apparent charge of phthalic acid $\left(\mathrm{A}^{2-}\right.$ form was from 0.698 to 0.998 mmol. $\mathrm{L}^{-1}$ when $\mathrm{pH}$ increase from 5.7 to 8), except for phosphate because negative charge density varies with $\mathrm{pH}$ [12]. It appears that phosphate anions $\left(\mathrm{H}_{2} \mathrm{PO}_{4}{ }^{-}\right.$form $)$are eluted first at pH 5.7 (Fig. 1) and just before sulfate anions $\left(\mathrm{HPO}_{4}=\right.$ form) at $\mathrm{pH} 8$ (Fig. 2c). Unfortunately, even though the six anions are well resolved at $\mathrm{pH} 5.7$ using standard solutions (Fig. 1), injection of a natural water sample can induce large perturbation at void volume (cations and carbonate ions) and the chloride and phosphate peaks can be hidden. If phosphate anion analysis is required, it is preferable to use 1 mmol.L ${ }^{-1}$ phthalic acid-TRIS pH 8 eluent.

If we compare conductivity and indirect photometric detection, it is well known that a great advantage of the latter is that it does not require a column oven and a stable baseline is obtained a few minutes after the detector is switched on. In this case, continual monitoring of the instrument is avoided unlike with conductivity detection. Modern conductivity dectectors, while having higher temperature

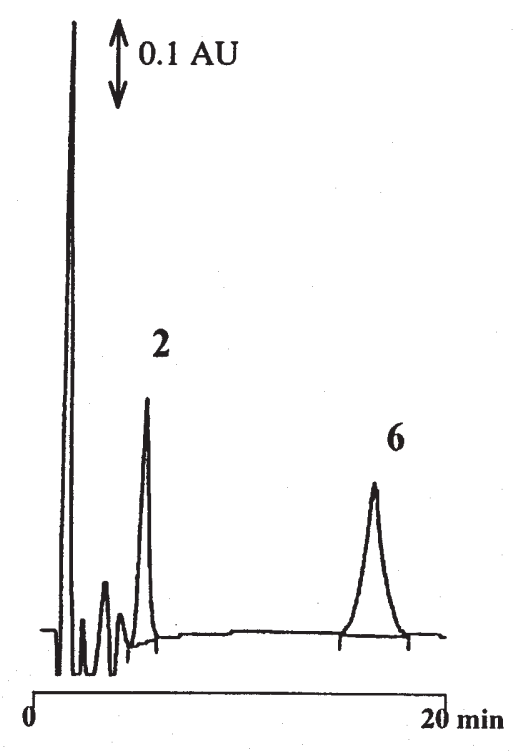

$\mathbf{a}$

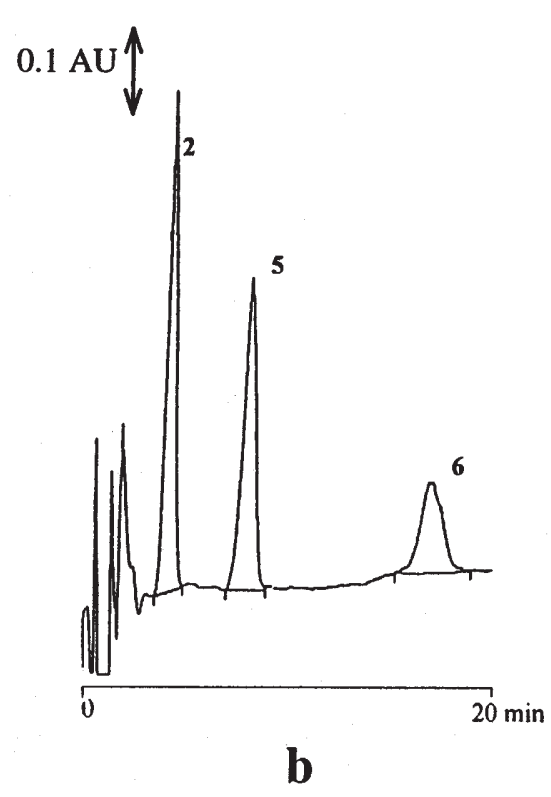

b

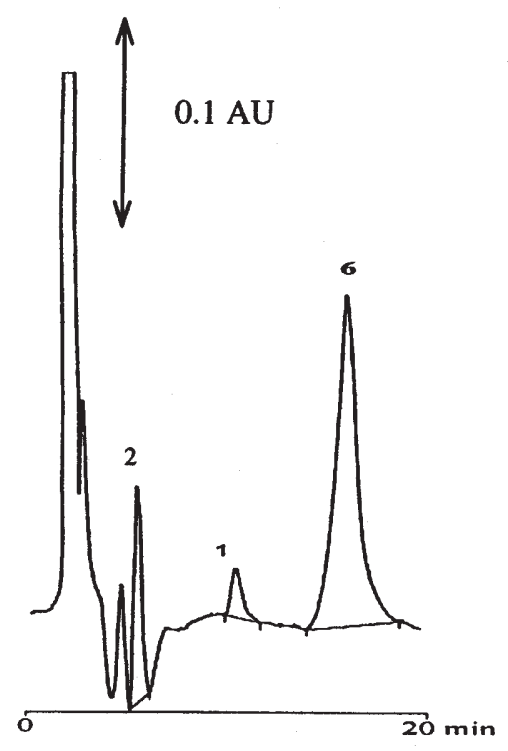

C

Fig. 2. Chromatograms of a drinking water (a), a ground water sample (b) and a 4.9 mg. $\mathrm{L}^{-1}$ phosphate spiked drinking water (c) using indirect photometric detection at $273 \mathrm{~nm}$. Water sample was diluted twice in distilled water. Conditions and solute identification as in figure 1 except eluent at $\mathrm{pH} 8$ for phosphate analysis in c. 


\section{Letter}

stability, are costly. In addition, phosphate anions induce a negative peak with conductivity detection (Fig. 1b). One other advantage of indirect photometric detection is that, if all the solutes are transparent at the detection wavelength, the response coefficients are very closed for all the solutes bearing the same charge [1].

Some applications are shown in figure 2. Since no phosphate was found in the samples, the pH 5.7 eluent was used for water samples (Fig. 2a and b). In drinking water (Fig. 2a), the chloride and sulfate anions concentrations found were 13.5 and $35.5 \mathrm{mg} . \mathrm{L}^{-1}$ respectively by conductivity detection and 15.2 and $36.1 \mathrm{mg} . \mathrm{L}^{-1}$ by indirect photometric detection. In ground water sample, the chloride, nitrate and sulfate concentrations found were 26.7, 47.0 and $17.2 \mathrm{mg} . \mathrm{L}^{-1}$ respectively by conductivity detection and 31.2 , 50.1 and $16.1 \mathrm{mg} . \mathrm{L}^{-1}$ by indirect photometric detection. The detection limit was approximately 25 and $3 \mu$ mole. $\mathrm{L}^{-1}$ for conductimetric and indirect photometric detections respectively but the former required longer equilibration time.

As far as phosphate detection is concerned (Fig. 2c), the concentration found in a spiked sample was $5.0 \mathrm{mg} . \mathrm{L}^{-1}$ for a real concentration of $4.9 \mathrm{mg} . \mathrm{L}^{-1}$.

\section{Conclusions}

Ion chromatography using new exchangers with low capacity as stationary phase and indirect photometric detection, without any temperature control, is an efficient and convenient system for the determination of main inorganic anions in water samples. Phosphate, for which the use of conductivity detection is very difficult, can be detected by absorbance lowering, as well as the other anions, using the adequate eluent composition. The system is stable and simple and can be used in teaching and industrial laboratories in the absence of special and quite expensive equipment.

\section{References}

1. Caude, M.; Rosset, R.; Jardy, A. Chromatographies en phases liquide et supercritique; 3th ed., Masson: Paris, 1991; pp 365457.

2. Lucy, C.A. J. Chromatogr. A 1996, 739, 3-13.

3. Jardy, A.; Caude, M.; Diop, A.; Curvale, C.; Rosset, R. J. Chromatogr. 1988, 439, 137-149

4. Munaf, E.; Zein, R.; Takeuchi, T.; Miwa, T. Chromatographia 1996, 43, 304-308.

5. Hou, J.-G.; Bian, H.-J.; Gao, J.-Z.; Kang, J.-W. Chromatographia 1996, 43, 473-476.

6. Small, H.; Miller, T.E. Anal. Chem. 1982, 54, 462.

7. Mongay, C.; Pastor, A.; Olmos, C. J. Chromatogr. A 1996, 736, 351-357.

8. Révész, G.; Hajos, P.; Csiszar, H. J. Chromatogr. A 1996, 753, 253-260.

9. Ding, M.-Y.; Chen, P.-R.; Luo, G.-A. J. Chromatogr. A 1997, 764, 341-345.

10. Waterworth, J.P. J. Chromatogr. A 1997, 770, 99-104.

11. Ivask, J.; Pentchuk, J. J. Chromatogr. A 1997, 770, 125-127.

12. Jupille, T.H.; Gjerde, D.T. J. Chrom. Sci. 1986, 24, 427. 